\title{
CUA Guideline: Management of ureteral calculi
}

\author{
Michael Ordon, MD, FRCSC; ${ }^{*}$ Sero Andonian, MD, FRCSC; ${ }^{+}$Brian Blew, MD, FRCSC,; \\ Trevor Schuler, MD, FRCSC, * Ben Chew, MD, FRCSC,* Kenneth T. Pace, MD, FRCSC*
}

*Division of Urology, Department of Surgery, University of Toronto, Toronto, ON; 'Division of Urology, Department of Surgery, McGill University, Montreal, QC; §Division of Urology, Department of Surgery, University of Ottawa, Ottawa, ON; *Division of Urology, Department of Surgery, University of Alberta, Edmonton, AB; "Department of Urology, University of British Columbia, Vancouver, BC

Cite as: Can Urol Assoc J 2015;9(11-12):E837-51. http://dx.doi.org/10.5489/cuai.3483 Published online December 14, 2015.

\section{Introduction}

A number of factors must be considered in determining the optimal treatment for patients with renal or ureteral calculi. These factors may be grouped into four broad categories: stone factors (location, size, composition, presence and duration of obstruction); clinical factors (symptom severity, patient's expectations, associated infection, obesity, coagulopathy, hypertension and solitary kidney); anatomic factors (horseshoe kidney, ureteropelvic junction obstruction and renal ectopia); and technical factors (available equipment, expertise and cost). ${ }^{1}$ When intervention is indicated, the factors above need to be considered in helping to select the treatment that will achieve maximal stone clearance with minimal morbidity to the patient. In many cases, more than one treatment option will be suitable and the ultimate treatment decision will be based on the patients' preferences with respect to the balance between invasiveness and morbidity of the procedure versus the likelihood of achieving stonefree status. Access to necessary equipment and technical expertise may also play a key role in the treatment options offered to patients.

The focus of this guideline is the management of ureteral stones. Specifically, the topics covered include: conservative management, medical expulsive therapy, active intervention with either shockwave lithotripsy (SWL) or ureteroscopy (URS), factors affecting SWL treatment success, optimizing success, and special considerations (e.g., pregnancy, urinary diversion). By performing extensive literature reviews for each topic evaluated, we have generated an evidence-based consensus on the management of ureteral stones. The objective of this guideline is to help standardize the treatment of ureteral stones to optimize treatment outcomes.

\section{Methods/guideline development process}

Separate reviews of the literature were performed for each of the major topic areas. English language publications from 2000 to 2014 were identified from Medline. For each topic, two authors independently performed the extensive literature review to ensure completeness. The International Consultation on Urologic Disease (ICUD)/WHO modified Oxford Center for Evidence-Based Medicine grading system was used to grade the quality of evidence for each topic assessed. Importantly, all recommendations were based on expert review of the literature and represent the consensus of all authors of these guidelines.

\section{Conservative management}

\section{Observation/spontaneous passage}

Conservative management to allow spontaneous stone passage is preferred provided that passage is likely in a reasonable time frame, with acceptable patient symptoms and a low risk of complications. Conservative management is not appropriate in the face of infectious symptoms, intolerable patient symptoms, or if conservative management would pose a potential threat to renal function.

Numerous case series have described rates of spontaneous passage based on stone size and location. We have found that $95 \%$ of ureteral stones 2 to $4 \mathrm{~mm}$ in size will pass spontaneously. This drops to $50 \%$ for stones greater than $5 \mathrm{~mm} .^{2}$ Stones greater than $6 \mathrm{~mm}$ have a lower rate of spontaneous passage. ${ }^{3}$ Duration of stone passage may be as long as 40 days. ${ }^{2}$ A meta-analysis of five series, with a total of 224 patients with stones less than or equal to $5 \mathrm{~mm}$ included in the 2007 American Urological Association (AUA)/European Association of Urology (EAU) ureteral stone guidelines, demonstrated a stone passage rate of $68 \%$ decreasing to $47 \%$ for stones 5 to $10 \mathrm{~mm}$ in diameter. ${ }^{4}$

In determining stone size, the axial diameter (i.e., width) of the stone on unenhanced computed tomography (CT), 
as opposed to the length, is closely correlated with stone passage rate. ${ }^{5}$ Furthermore, if coronal reconstruction images are available, they can provide additional information with respect to the maximal stone diameter. ${ }^{6}$ Also of note, ultrasound has been shown to overestimate stone size, particularly for stones $\leq 5 \mathrm{~mm}$, compared with CT scan, ${ }^{7}$ and so if available, CT-based measurement of stone size should be relied upon for determining a treatment plan.

Recommendation: Spontaneous passage of stones less than $5 \mathrm{~mm}$ in size in the distal ureter have a $>90 \%$ chance of spontaneous passage within $\mathbf{4 0}$ days and are appropriate for an attempt at conservative management provided there are no infectious symptoms, intolerable patient symptoms or a threat to renal function. Stones above $5 \mathrm{~mm}$ in diameter are less likely to pass spontaneously and patients should be counselled about treatment options (Level of Evidence 4, Grade C).

\section{Medical expulsive therapy}

Calcium channel blockers and alpha-receptor antagonists have been studied as adjuncts to improve rates of ureteral stone passage and shorten time to stone passage. The 2007 AUA/EAU ureteral stone guidelines performed a meta-analysis of medical expulsive therapy trials using these agents. Calcium channel blockers did not demonstrate a statistically significant improvement in stone passage whereas significantly more (29\%; confidence interval [CI] 20\%-37\%) patients passed their stones with alpha-blocker therapy than did patients receiving a placebo. ${ }^{4} \mathrm{~A}$ Cochrane collaboration meta-analysis demonstrated a higher stone-free rate (RR $1.48,95 \% \mathrm{Cl} 1.33-1.64$ ), a shorter time to stone passage (2.91 days less), with a decreased number of pain episodes, analgesic requirements and hospitalizations for patients with ureteral stones less than $10 \mathrm{~mm}$ treated with alpha-receptor antagonists compared to placebo. ${ }^{8}$ Conversely, a recent large randomized controlled trial failed to show any benefit from the use of tamsulosin or nifedipine to promote stone passage ${ }^{9}$.

\begin{tabular}{|c|c|c|}
\hline \multirow[t]{2}{*}{ Stone location/size } & \multicolumn{2}{|c|}{ Stone-free rate* } \\
\hline & SWL & URS \\
\hline ureter & $74 \%$ & $94 \%$ \\
\hline$\leq 10 \mathrm{~mm}$ & $86 \%$ & $97 \%$ \\
\hline$>10 \mathrm{~mm}$ & $74 \%$ & $93 \%$ \\
\hline Mid ureter & $73 \%$ & $86 \%$ \\
\hline$\leq 10 \mathrm{~mm}$ & $84 \%$ & $91 \%$ \\
\hline$>10 \mathrm{~mm}$ & $76 \%$ & $78 \%$ \\
\hline Proximal ureter & $82 \%$ & $81 \%$ \\
\hline$\leq 10 \mathrm{~mm}$ & $90 \%$ & $80 \%$ \\
\hline$>10 \mathrm{~mm}$ & $68 \%$ & $79 \%$ \\
\hline
\end{tabular}

SWL: shock wave lithotripsy; URS: ureteroscopy; ${ }^{*}$ Stone free rate following first treatment or primary treatment is reported.
Ultimately, when reviewing all of the available literature there is likely to be a benefit for alpha blockers in treating distal ureteral calculi less than $10 \mathrm{~mm}$. However, clinicians should always weigh the risks and benefits of therapy. Since the risks of alpha-blockers are low, they likely remain an important aspect of medical expulsive therapy.

Recommendation: Medical expulsive therapy with alphareceptor antagonists potentially shortens the duration and increases the likelihood of spontaneous stone passage. Consideration should be given to offering it to patients with distal ureteral stones less than $10 \mathrm{~mm}$ in size (Level of Evidence 1a, Grade A).

\section{Comparative outcomes of SWL vs. URS}

SWL and URS are the two main modalities presently used to treat ureteral calculi in an attempt to achieve the goal of maximal stone clearance with minimal morbidity to the patient. Below, the stone-free rates and complications of SWL and URS are reviewed with results stratified by stone location and size.

In 2007 the AUA and EAU joined forces to publish the 2007 Guideline for the Management of Ureteral Calculi, ${ }^{4}$ which represented a synthesis of the best available evidence at the time comparing outcomes for SWL to URS. This joint EAU/AUA Nephrolithiasis Guideline Panel performed a systematic review of the English language literature published since 1997 and comprehensively analyzed outcomes data from the identified studies. The meta-analysis revealed that for stones in the proximal ureter, there was no difference in stone-free rates between SWL and URS. However, for proximal ureteral stones $<10 \mathrm{~mm}$, SWL had a higher stone-free rate than URS ( $90 \%$ vs. $80 \%$ ), whereas for stones $>10 \mathrm{~mm}$, URS had superior stone-free rates (79\% vs. $68 \%)$. As such, the guidelines offer both SWL and URS as equal first-line options for proximal ureteral stones. This contrasts to the previous guidelines from 1997 where SWL was the only first-line option for proximal ureteral stones. In the updated guidelines, the stone-free rate for mid-ureteral stones was not statistically significantly different between URS and SWL, whereas for distal stones, URS yielded better stone-free rates overall and in both size categories (Table 1).

Since the publication of AUA/EAU guidelines in 2007, two more recent systematic reviews and meta-analyses have been completed.

First, a Cochrane review, published in 2012, analyzed seven randomized controlled trials (RCTs) comprising 1205 patients treated for ureteric stones. ${ }^{10}$ The stone-free rates were lower for SWL when compared with URS (RR 0.84, $95 \% \mathrm{Cl} 0.73-0.96)$. Consequently, the need for retreatment, defined as a subsequent intervention for the stone using the same therapeutic technique as the initial treatment, was higher in SWL patients (RR 6.18,95\% Cl 3.68-10.38). ${ }^{10}$ 
Procedure-related complications were lower for SWL compared to URS patients (RR $0.54,95 \% \mathrm{Cl} 0.33-0.88$ )..$^{10}$

Second, a meta-analysis by Matlaga and colleauges ${ }^{11}$ stratified their analysis of SWL versus URS based on stone location in the distal versus proximal ureter. They also specifically compared URS both to SWL with the Dornier HM3 and to other lithotripters. Considering no $\mathrm{HM} 3$ lithotripters are in use in Canada, we present only the results of URS versus other lithotripters. For distal ureteral stones, analysis of six studies revealed a 55\% greater probability of being stone-free at first follow-up with semi-rigid URS compared with SWL (RR 1.55). However, with time, SWL approached the stone-free rate of semi-rigid URS due to re-treatment of SWL cases. Accordingly, patients treated with semi-rigid URS were less likely to require re-treatment than patients treated with SWL for distal ureteral stones (RR 0.14). A similar number of complications occurred in both the semi-rigid URS and SWL groups (pooled RR 1.28, 95\% CI 0.94-1.81). For proximal ureteral stones, there was a greater probability of being stone-free with semi-rigid URS versus SWL (RR 1.15 ) and a lower risk for retreatment (RR $0.08,95 \% \mathrm{Cl}$ 0.02-0.32). However in this meta-analysis, no studies directly compared semi-rigid URS to SWL for proximal ureteral stones and as such this is a comparison of outcomes across different studies, which is methodologically undesirable.

Unfortunately, the marked heterogeneity of the existing evidence in terms of study design, stone location, types of ureteroscope, intracorporeal lithotripsy devices, policy variations in stenting after ureteroscopy, and time to follow-up limit the conclusion that can be drawn from both of the aforementioned meta-analyses. Accordingly, it is difficult to provide a definitive recommendation for use in clinical decision-making.

Ultimately, the size and location of stones, the urologist's expertise and the availability and access to resources and appropriate technologies remain the principal criteria to inform treatment choice for the management of ureteric stones. Large, multicentre, well-designed RCTs and high quality reporting are lacking in the medical literature.

Recommendation: Both SWL and URS are safe and efficacious treatment options for ureteral stones. Based on the available evidence, patients who undergo URS have a higher likelihood of achieving stone-free status, especially for distal stones, at the expense of a greater risk of complications. Patients should be offered both options when suitable and available, and educated on the benefits and risk of each treatment modality (Level of Evidence 2a, Grade B).

\section{Other factors affecting SWL treatment success}

Beyond location in the ureter, other stone-related factors, including composition, density of the stone, and skin-tostone distance on $\mathrm{CT}$, may influence the treating physician and patient's discussion regarding the choice to proceed with either SWL or URS.

\section{Composition}

Most stones, composed of calcium oxalate, will fragment well with SWL treatment. There are certain stone compositions, such as cystine, calcium oxalate monohydrate and brushite, that are more resistant to SWL and may be better served by ureteroscopic management. ${ }^{12}$ Moreover, in the case of cystine and calcium oxalate monohydrate, the fragments created by SWL may be large which can result in poor clearance. Uric acid stones, while fragile in the face of SWL, present a challenge with respect to localization for SWL treatment. Either the use of ultrasound or pyelography (IVP or retrograde) is required to target the stone. In addition, follow-up cannot be completed in the conventional fashion with plain radiography, and requires the use of either ultrasound or, more often, CT scanning to ensure the patient is successfully treated.

In many instances the exact stone composition will not be known prior to treatment, or in the case of recurrent stone formers, it may have changed over time. ${ }^{13}$ Non-contrast CT scans using dual energy can distinguish some types of stones in vivo. Uric acid stones can be differentiated from calcium stones; however, there is significant overlap in the attenuation of calcium-based stones which makes determining the exact composition difficult. Recent publications on dual energy CT scanning support that different calcium stone compositions can be determined, however this modality is not readily available in clinical practice. ${ }^{14,15}$

\section{Stone density}

As a surrogate for composition, several authors have postulated that the fragmentation of stones with SWL could be predicted based on the measurement of stone density on CT expressed in Hounsfield units (HU). A linear relationship exists between increased stone density and poor stone fragmentation with a threshold of $1000 \mathrm{HU}$, above which stones are less likely to be successfully fragmented with SWL. 16,17 Two prospective studies reinforced these findings with respect to stone densities greater than $1000 \mathrm{HU}$ and 970 HU. ${ }^{18,19}$

When measuring $\mathrm{HU}$, it is best to maximally magnify the image on the stone, use bone windows, and draw an ellipse within the stone.

\section{Skin-to-stone distance (SSD)}

In addition to providing information on stone size and density, CT scans can also allow for measurement of SSD. Several groups have reported reduced SWL success in 
patients with a greater SSD and high stone density. A large retrospective Canadian series, including renal and ureteral stones, demonstrated on multivariate analysis that a SSD of greater than $11 \mathrm{~cm}(\mathrm{OR} 0.49, \mathrm{Cl} 0.31-0.78)$ and density greater than $900 \mathrm{HU}(\mathrm{OR} 0.49, \mathrm{Cl} 0.32-0.75)$ were significant predictors of SWL failure. ${ }^{20} \mathrm{~A}$ second large retrospective review of $1282 \mathrm{SWL}$ treatments also demonstrated on multivariate analysis that SSD greater than $10 \mathrm{~cm}$ was associated with lower stone-free rates. ${ }^{21}$

Recommendation: Stone composition, stone density and skin-to-stone distance should be used when possible to counsel patients regarding the success of SWL treatment for patients presenting with ureteral stones. Known cystine, calcium oxalate monohydrate, and brushite stones are likely best treated with URS. Patients with ureteral stones with a density greater than $1000 \mathrm{HU}$ or SSD greater than $10 \mathrm{~cm}$ are more likely to fail SWL and may be better served with URS (Level of Evidence 2b, Grade B).

\section{Optimizing treatment outcomes}

\section{Shockwave lithotripsy}

Despite the advances in ureteroscopes, holmium laser, and endoscopic instrumentation, SWL remains a first-line treatment modality for ureteral calculi. SWL outcomes can be directly influenced by case selection, surgeon technique, and modifiable parameters to enhance safety and maximize successful outcomes. Most of the data for SWL outcomes is derived from patients with renal (rather than ureteric) calculi, but these findings should be generalizable to ureteric stones, particularly for those in the upper ureter, where renal parenchyma is included in the blast path of the shock wave energy.

\section{Coupling}

Coupling of the SWL generator head to the patient in an airtight manner, with minimization of gas and air bubbles in the coupling media, is critical to maximizing energy delivery to the stone. Failure to recognize breaks in coupling can lead to failure of stone fragmentation. Changes in lithotripter design have led to a move away from water bath coupling (as was seen with the original HM3 design) to the use of a smaller coupling interface. Coupling can be influenced by the type of SWL machine, type of gel used at the patientgenerator interface (a greater volume of lower-viscosity gel being preferable), method of application of that gel (best to apply to shock head first), and patient factors (patient movement during treatment, lifting of the back off the generator leading to "decoupling" and introducing air bubbles into the coupling interface).22-26
Recommendation: SWL operators should ensure proper patient coupling to reduce air bubbles in the SWL blast path, particularly near the centre of the blast path. Patients should receive adequate anesthesia and analgesia to prevent patient movement and "decoupling" during treatment (Level of Evidence 4, Grade C).

\section{Targeting}

Proper stone targeting is vital for SWL success. Whether fluoroscopic or ultrasound targeting is superior is an ongoing debate, and varies with urologist expertise, SWL machine type, and stone composition. ${ }^{27}$ Real-time, in-line imaging is generally considered superior, however in-line (or coaxial) ultrasound imaging is not available with all units. Respiratory excursion hinders targeting by reducing the time that the stone is within the SWL focal zone, even with ideal targeting. Shock wave triggering based on respiration has been abandoned because of increased treatment time, but compression belts reduce renal movement with respiration. Targeting should be confirmed at regular intervals throughout treatment. ${ }^{28}$ Greater use of fluoroscopy time can lead to improved outcomes. ${ }^{29,30}$

Recommendation: SWL targeting (whether fluoroscopic or ultrasonic) should occur at regular intervals throughout the treatment. Compression belts may help reduce renal (and ureteric) excursion with treatment (Level of Evidence 4, Grade C).

\section{Dose escalation/pause}

SWL energy should be maximized during treatment in order to maximize stone comminution. This is particularly true for mid and distal ureteral stones, where the renal parenchyma is not included in the blast path and thus the risk of renal injury is negligible. However, particularly for upper ureteric stones, SWL energy should be increased gradually, rather than beginning at maximum energy. This allows for better patient accommodation to the sensation of treatment (when treatment is performed under intravenous sedation). This also reduces renal injury by inducing renal vasoconstriction, which is protective in reducing the rate of renal hematomas. ${ }^{31-35}$ An alternative strategy is to pre-treat the kidney with a series of low energy shocks and then pause treatment for a short period of time before resuming at higher energy levels. ${ }^{31}$ Of note, if fragmentation is seen at lower energies it is not necessary to increase the energy any further.

Recommendation: Patients with upper ureteric stones should initially receive low-energy shocks, with gradual voltage escalation up to maximum energy (Level of Evidence $1 \mathrm{~b}$ and 4 , Grade $\mathrm{C}$ ). 


\section{Number of treatments}

Not all SWL treatments of ureteric stones will be successful and render the ureter stone free. When treatment is unsuccessful, a decision must be made whether to retreat with SWL or to switch to endourologic treatment (retrograde or antegrade URS). This decision-making is often influenced by the degree of fragmentation with the initial SWL session, and by patient factors (patient preferences, impending travel, importance of being rendered stone free quickly, dislike of ureteric stent and prior patient treatment experience). In general, if SWL fails it can be repeated, but the incremental benefit of more than two SWL treatments for the same ureteric stone is small. ${ }^{36,37}$ Accordingly, after two unsuccessful SWL treatments, consideration should be given to alternative treatment with ureteroscopy. The optimal time interval between SWL treatments is unclear, but can be as short as within two days for mid and distal ureteric stones. Recommendation: If $S W L$ is unsuccessful, the urologist may elect to treat the stone a second time with SWL in consultation with the patient. More than two SWL treatments to the same ureteric stone have little incremental benefit and URS should be considered (Level of Evidence 4, Grade C).

\section{Treatment rate}

A number of randomized trials have indicated that reducing shock wave rate from 120 shocks/min can improve stone fragmentation, particularly for stones larger than $1 \mathrm{~cm} \cdot{ }^{38-43}$ This may also reduce the degree of renal injury, which may be an issue for upper ureteric stones, but is likely less relevant for mid and distal ureteral stones. Slowing treatment rate does increase treatment times. The optimal treatment rate is not clear; however, studies suggest that SWL at 60 to 90 shocks/ min leads to better fragmentation than 120 shocks/min, particularly for larger stones. ${ }^{43-45}$ Most studies were performed with renal calculi; however, improved outcomes have been demonstrated for upper ureteric stones as well. ${ }^{39}$

Recommendation: Patients with upper ureteric stones $>1$ $\mathrm{cm}$, or stones that have failed prior treatment, should be treated with a SWL rate of less than 120 shocks/min (Level of Evidence 1b, Grade A).

\section{Alpha blockers}

Given the initial reports showing a benefit with oral alpha blockers in enhancing the spontaneous passage of ureteral stones, several authors have studied the effect of alpha blockers administered as an adjunct to SWL to improve stone-free rates. Their work has been summarized in two meta-analyses with similar findings. The first in 2009 combined the results of four studies, which randomized patients to receive medical expulsive therapy versus placebo or standard of care post treatment. Two of the four studies used tamsulosin, while one used a calcium channel blocker and the other an herbal agent (phyllanthus niruri). ${ }^{46-50}$ The use of medical expulsive therapy was associated with a $17 \%$ increase in SWL success rates with a number needed to treat of six. A more recent meta-analysis focused solely on the use of alpha blockers post-SWL and had similar findings. The authors identified seven trials that met the inclusion criteria and found that the use of alpha-blockers, which was tamsulosin in all seven studies, improved SWL success by $16 \% .^{47,51-57}$ The authors also reported reduced time to fragment passage, reduced pain, and required less analgesia.

Alpha blockers are well-tolerated, inexpensive, and familiar to urologists. The use of alpha blocker therapy as an adjunct to $S W L$ should result in increased fragment passage and a reduction in the need for repeat $S W L$ or more invasive treatments, such as URS. Additional benefits with respect to less pain and reduced need for analgesic use may also be realized.

Recommendation: Alpha blockers, in particular tamsulosin, should be prescribed to patients after SWL for ureteral stones to improve treatment success rates (Level of Evidence 1a, Grade A).

\section{Number of shocks}

The optimal number of shocks to administer has not been definitively established. In principle, urologists must balance treatment efficacy with adverse effects (particularly renal damage). For mid to distal ureteric stones, where the renal parenchyma is not affected by SWL energy, treatment can safely be carried out up to 4000 or more shocks. ${ }^{37}$ However, the incremental benefit of treating ureteric stones beyond 4000 shocks has not been established. For upper ureteral stones the range is from 2000 to 3500 shocks. ${ }^{37}$ In general, urologists should follow their lithotripter manufacturer's recommendations for the optimal maximum number of shocks. Recommendation: An adequate number of shocks should be administered to ensure adequate treatment of ureteric stones. This number varies based on recommendations from the specific SWL machine manufacturers, but generally ranges from 2000 to $\mathbf{4 0 0 0}$ shocks for ureteric stones (Level of Evidence 4-5, Grade D).

\section{Stenting}

There is good evidence to show that ureteral stenting is not necessary in SWL ${ }^{58}$ and does not improve the success rate or passage of fragments. ${ }^{59}$ In fact, having a stent may impede the passage of fragments following SWL. A trial consisting of patients with ureteral stones between 4 to $10 \mathrm{~mm}$ undergoing SWL were randomized to a stent or no stent. ${ }^{60}$ The stone-free rate was much lower in stented patients $(68.6 \%)$ 
than non-stented patients $(83.7 \%, p=0.026)$. Consequently, stented patients required significantly more adjuvant procedures to render them stone free compared to non-stented patients. On multivariate analysis, the authors noted that the location of the stone, size of stone and presence of a stent were the three factors that significantly affected stonefree rate. Further supporting this, Argyropoulos and Tolley looked at SWL of ureteral stones with a mean size of 8.5 $\mathrm{mm}$ in diameter and found that the stone-free rate in stented patients was significantly lower $(71 \%)$ compared to those who were not stented $(93 \%){ }^{61}$

In addition, based on the available evidence, stents do not appear to decrease the risk of steinstrasse or infection following SWL. ${ }^{62-64}$

However, consideration should still be given to placing a stent prior to SWL in patients with a solitary kidney.

Recommendation: Ureteral stents do not improve the stone-free rates in SWL and actually impede the passage of fragments resulting in lower stone free rates (Level of Evidence 1a, Grade A). They should be used prior to SWL to treat obstruction, acute kidney injury, intolerable pain, sepsis, and in those with a solitary kidney. If inserted for sepsis, a course of antibiotics should be given prior to $S W L$ and the patient should not be exhibiting signs of sepsis at the time of treatment (Level of Evidence 5, Grade D). Stents do not decrease the risk of steinstrasse or infection following SWL (Level of Evidence 1a, Grade A).

\section{Ureteroscopy}

\section{Lithotrite (laser vs. electrohydraulic vs. pneumatic)}

Common methods of intracorporeal ureteroscopic lithotripsy include pneumatic, eletrohydraulic, and Holmium:YAG (Ho:YAG) laser. Treatment of ureteral stones with Ho:YAG lithotripsy is superior $(p<0.05)$ to pneumatic lithotripsy when comparing stone-free rate $(95-98.6 \%$ vs. $80-86 \%)$, ${ }^{65-}$ ${ }^{68}$ operative time (15-20 vs. $25-33$ mins), ${ }^{68,69}$ and need for auxiliary treatment, such as SWL or repeat URS (2\%-2.5\% vs. $14 \%-17.5 \%) .{ }^{65,66}$ When compared with electrohydraulic lithotripsy, Ho:YAG laser lithotripsy was demonstrated to have superior stone-free rates for stones larger than $15 \mathrm{~mm}$ (100\% vs. 67\%) and faster operative time for stones less than $15 \mathrm{~mm}$ (72 vs. $102 \mathrm{~min}){ }^{70}$ Available studies are not sufficiently powered to conclude if a significant difference exists in complication rates such a ureteral perforation, stone migration, or delayed ureteric stricture.

Recommendation: Holmium:YAG laser lithotripsy offers superior stone fragmentation, stone free rates and minimizes the need for auxiliary procedures. It should be considered the method of choice for intracorporeal lithotripsy of ureteral stones (Level of Evidence 2b, Grade B).

\section{Ureteral access sheath}

The use of a ureteral access sheath (UAS) has traditionally been advocated at the time of flexible URS for renal stones for several reasons, including: (1) facilitating flexible URS by allowing easy multiple entry and re-entry to the upper urinary tract and renal collecting system; (2) decrease in intrarenal pressure, which could potentially diminish kidney injury; ${ }^{71,72}$ (3) improved irrigation flow thus optimizing vision; ${ }^{71}$ and (4) the potential to improve stone-free rates by allowing passive egress or active retrieval of fragments. However, the impact of UAS on stone-free rates is unclear, as the evidence is very limited. ${ }^{73-75}$

The effect of UAS use on the ureter is also unclear. It has been demonstrated in animal models that the UAS can induce transient ureteral ischemia and promote an acute inflammatory response in the ureter. ${ }^{76}$ Furthermore, a recent prospective study has questioned the safety of the UAS, demonstrating the potential for ureteral wall injury in $46.5 \%$ of patients. ${ }^{77}$ However, no randomized trials exist comparing the incidence of ureteral stricture with and without a UAS. Retrospective studies show no increased risk of stricture formation.

Ultimately and unfortunately, much of the current data with respect to UAS use are limited by the fact they come from non-randomized studies that are largely retrospective in nature with short follow-up. This limits the recommendations that can be made.

Recommendation: Further studies are needed to confirm safety, define cost-effectiveness, and determine the clinical impact of the reduction of ureteral and intrarenal pressures during sheath deployment before any definitive recommendation on the use of the UAS can be made. Nevertheless, the UAS remains a highly useful tool in the armamentarium of the urologist during flexible URS (Level of Evidence 4, Grade C).

\section{Ureteroscope size}

The outer tip diameter of ureteroscopes typically varies between 4.5 and $8.5 \mathrm{Fr}$. for semi-rigid ureteroscopes and 6.75 to $8.7 \mathrm{Fr}$. for flexible ureteroscopes. Recently, digital flexible ureteroscopes have come into more widespread use providing excellent visualization, but some have a larger diameter (8.7Fr. tip with 9.9Fr. shaft), which can make insertion into the non-dilated ureter more difficult. Furthermore, the durability of flexible digital ureteroscopes compared to fibreoptic ureteroscopes remains to be seen.

\section{Semi-rigid ureteroscopes}

Semi-rigid (SR) ureteroscopes represent the mainstay for treating most ureteric stones in light of the superior optics, 
excellent irrigant flow and size of the working channel. Stone-free rates are equivalent between small SR ureteroscopes (4.5-7.5Fr tip) and larger SR ureteroscopes (8.5-10 Fr tip). ${ }^{78,79}$ Larger SR ureteroscopes may require more ureteric dilation and increase minor complications of mucosal abrasion or postoperative hematuria. ${ }^{79}$

\section{Flexible ureteroscopes}

Flexible fibreoptic ureteroscopes range in size from 7.4 to 9.0Fr in diameter and have a progressively higher rate of insertion failure into the undilated ureteral orifice, increasing from $0.9 \%$ to $37 \%$, respectively, dependent on size. ${ }^{80}$ With the introduction of flexible digital ureteroscopes, with typical tip diameters of 8.4 to $8.7 \mathrm{Fr}$ broadening to a $9.9 \mathrm{Fr}$ shaft, there is an increasing need for ureteral orifice dilation and access sheath use. ${ }^{81}$ In addition, the greater diameter may result in a higher likelihood of being unable to access and treat stones in the proximal ureter or renal pelvis/calyces. However, based on the available studies comparing larger digital flexible ureteroscopes with fibreoptic flexible ureteroscopes, the larger diameter did not affect stone-free rates and the digital ureteroscope resulted in shorter operative times. ${ }^{82,83}$

Recommendations: Within the range of commercially available semi-rigid and flexible ureteroscopes, the available evidence suggests stone-free rates and complication rates are similar. When available, use of smaller ureteroscopes may lessen the need for ureteral dilation and slightly reduce minor postoperative complications such as hematuria (Level of Evidence 4, Grade C).

\section{Stenting}

\section{Pre-stenting prior to ureteroscopy}

Ureteral stents are often placed at the completion of a ureteroscopic case. However, this discussion addresses "prestenting" of a patient prior to a planned URS. Ureteral stents are known to provide drainage, as well as passively dilate the ureter. Accordingly, pre-stenting prior to URS has been shown to ease the insertion of ureteroscopes and UAS. Prestenting did not affect stone-free rates in patients with stones less than $1 \mathrm{~cm}$, but in patients with stones greater than 1 $\mathrm{cm}$, the stone-free rate was significantly better (95.8\%) after a single treatment. ${ }^{84}$ The same study also performed a cost analysis and in those patients with a stone greater than 1 $\mathrm{cm}$, there was a decrease in overall costs to successfully treat the patient from $\$ 27806$ (not pre-stented) to $\$ 17706$ (pre-stented). Pre-stented patients required less adjuvant procedures to render them stone free, which accounted for the cost savings. Another study found that pre-stented patients had significantly higher stone free rates for ureteral stones $5 \mathrm{~mm}$ or greater $(99 \%$ vs. $90 \%, p=0.048) .{ }^{85}$ There was no difference in stone-free rates for ureteral stones smaller than $5 \mathrm{~mm}$ and no difference in complication rates for stones of any size.

Pre-stenting can also be effective in situations where the ureter is narrow and insertion of a UAS or ureteroscope is difficult. In these instances, placing a ureteral stent to help passively dilate the ureter and re-attempting URS at a later date is highly recommended to improve the rate of ureteral access and reduce the rate of complications. Balloon dilation and URS has been shown to be safe and effective in one sitting, but it must be recognized that if this does not work, stenting and performing URS after passive dilation is necessary. ${ }^{86}$

In a tertiary referral centre examining 119 consecutive patients, the rate of failure to access leading to a ureteral stent with delayed URS was $8 \%{ }^{87}$ A study of 41 patients with this scenario showed that $71 \%$ underwent secondary URS with ease, while 12 patients (29\%) had continued resistance. ${ }^{88}$ Of the 12 patients with continued resistance, nine underwent URS in the secondary setting and two of these patients subsequently developed a ureteral stricture. Overall, in this series of patients who underwent stenting for initial resistance in passing a ureteroscope, 98\% had successful subsequent URS. Care should be taken to avoid continuing despite resistance as this can lead to subsequent ureteral stricture, particularly with one-step dilation using a UAS. ${ }^{77}$ Pre-stenting before the use of a UAS decreased the rate of complication by sevenfold in this particular study. ${ }^{77}$ Preoperative discussion in consenting patients should include the potential of failed access, placement of a ureteral stent, and delayed URS at another date.

\section{Stenting post ureteroscopy}

Stenting post-ureteroscopy is not always necessary. The first description and randomized trial of stent versus stentless URS were both performed in Canada. Hosking and colleagues were the first to describe stentless URS in 93 patients undergoing URS for distal ureteral stones without any further intervention or requirement for subsequent stents or nephrostomy tubes. ${ }^{89}$ Denstedt and colleagues performed the first prospective randomized trial of stent versus no stent following URS. ${ }^{90}$ At one week following URS, patients without a stent had significantly less flank pain, abdominal pain, and dysuria compared to stented patients. There were no complications in those who did not have a stent. A subsequent meta-analysis showed an absolute lower risk of complications in those patients who were stented; however, this became insignificant on multivariate-analysis. ${ }^{91}$ Many other studies have shown no complications and less symptoms in those who did not receive a ureteral stent. ${ }^{92}$ Stenting after 
uncomplicated URS did not alter the stone-free rate, complications, urinary tract infection, unplanned medical visits, or fever.

Even when the ureteric orifice has been balloon-dilated to $18 \mathrm{Fr}$, stenting has not been shown to be beneficial. A randomized trial of 144 stented and 142 non-stented patients following rigid URS in which all patients were dilated to $18 \mathrm{Fr}$ was undertaken. ${ }^{93}$ These researchers found no differences in complications or strictures; however, they did find that stented patients had more irritative voiding symptoms (dysuria and urgency).

Another study undertaking SR URS using pneumatic lithotripsy showed that stented patients actually did better than non-stented patients..$^{94}$ Non-stented patients were more than twice as likely to visit the emergency department following discharge and they also took a longer time to discharge from the hospital on the day of surgery. Narcotic use was also significantly higher in the non-stented group in the first five days after surgery. This study showed evidence that stented patients were actually more comfortable and required less medical attention and narcotics following URS.

If bilateral URS is performed, depending on the situation, consideration should be given to stenting at least one side, to prevent the possibility of bilateral ureteric obstruction postoperatively.

\section{Stenting following use of a UAS}

If a UAS is used during URS, there is good data to support placing a ureteral stent in those cases. In a retrospective study of 102 patients, where 51 had no stent following UAS use and the other half were stented, stented patients were less likely to have unscheduled emergency visits and had lower pain scores compared to their non-stented counterparts. ${ }^{95}$ This was also corroborated by Canadian data where patients who did not have a ureteral stent were more likely to have an emergency room visit in the postoperative period $(37 \%$ vs. $14 \%, p=0.04){ }^{96}$

\section{Duration of stenting}

There is no prescribed indwelling time to leave a ureteral stent. The literature is scant regarding this issue. One study retrospectively analyzed 125 patients and found that stents that remained in less than 14 days had less adverse events, such as fever and lumbago, and the authors advocated less than two weeks of stenting following uncomplicated URS. ${ }^{97}$ Recommendation: Stenting following uncomplicated URS is still a controversial topic and there is evidence to support both sides. There is good evidence that ureteral stents should be left in place following use of a ureteral access sheath with URS. Stenting does not affect stone-free rates or long-term complications such as strictures, but may result in less emergency room visits and narcotic use in the postoperative period. Stenting prior to URS is helpful to improve stone-free rates in stones greater than $1 \mathrm{~cm}$. Stenting prior to URS also facilitates access to the ureter due to passive dilation (Level of Evidence 2a-2b, Grade B).

\section{Special considerations}

\section{Pregnancy}

No Level 1 Evidence exists regarding the treatment of ureteral stones during pregnancy. Retrospective case series provide some guidance on how to manage this situation. The first diagnostic step in suspected nephrolithiasis during pregnancy should be ultrasound due to the lack of radiation; however, ultra-low dose CT or magnetic resonance imaging (MRI) are good alternatives with very little or no radiation. ${ }^{98,99} \mathrm{~A}$ special protocol involving magnetic resonance urography (MRU) involves a half Fourier single-shot turbo spin-echo (HASTE), which is better at imaging ureteral stones than other MRU protocols. ${ }^{100}$

Most ureteral stones will pass spontaneously and the first option in management is conservative therapy, including hydration and analgesia. ${ }^{101}$ In a recent study, conservative management was successful in $67 \%$ of patients, who had symptomatic obstructing ureteral stones with an average stone size of $8.8 \mathrm{~mm} .{ }^{102}$ Immediate causes for intervention are the same as those in non-pregnant situations (signs of sepsis, renal failure, and unrelenting pain, etc.), but also include induction of premature labour (contractions, fetal distress) in the pregnant patient. ${ }^{103}$ The most immediate method of intervention is nephrostomy tube or ureteral stent insertion.

Failing conservative management, ureteroscopic treatment of stones using laser lithotripsy with either flexible or SR URS is feasible and safe. ${ }^{104}$ In fact, if ultrasound imaging is non-diagnostic and low-dose CT or MRI is unavailable, URS can also be used for both diagnostic and therapeutic purposes. ${ }^{102}$ A number of studies have demonstrated that URS is a viable technique to treat stones in pregnancy. ${ }^{102,105,106}$ Postoperative stenting following URS in this situation is recommended in an attempt to reduce postoperative complications. ${ }^{102}$ Ideally ureteroscopic treatment should be performed in the second trimester, as teratogenic effects and risks of anaesthesia are higher in the first trimester. ${ }^{103}$

With regards to intraoperative imaging, if URS or ureteral stent insertion is undertaken, then a lead apron or shield should be put between the $x$-ray fluoroscopy source and the fetus to shield it from radiation. ${ }^{107}$ These authors describe inverting the fluoroscopy $\mathrm{C}$-arm so that the energy source is above the supine patient and placing two thyroid collars on 
the anterior portion of the patient's abdomen to shield the fetus. This can also be achieved by placing the lead shield or apron underneath the patient if the C-arm energy source comes from below the table; this method also reduces radiation and scatter to operating theatre personnel. Alternatively, URS or ureteral stent insertion can be performed under ultrasound guidance alone, avoiding radiation exposure.

Pregnancy is a contraindication to SWL and although there have been reports of the inadvertent treatment of pregnant patients with $S W L$, with no adverse sequelae to the fetus, ${ }^{108}$ it should be avoided. Similarly, percutaneous nephrolithotomy (PCNL), if necessary, should be delayed until after birth as the procedure requires prolonged anaesthesia and radiation exposure.

Recommendation: First-line diagnostic testing for stones in pregnancy is ultrasound, but low-dose CT or MRI can also be used. In some instances, URS can also be diagnostic, as well as therapeutic. Obstructing ureteral stones are typically managed conservatively in the absence of fever, leukocytosis or positive urine culture. In those patients presenting with signs of sepsis, antibiotics and urinary decompression via a nephrostomy tube or ureteral stent are of primary importance. Definitive therapy should be delayed until the infection is treated. URS and laser lithotripsy is safe in pregnancy; however SWL and PCNL are contraindicated in pregnancy (Level of Evidence Level 4, Grade C).

\section{Anti-coagulation}

There is little literature regarding surgical management of stone patients with coagulopathies or on anticoagulation therapy. SWL, laparoscopic, percutaneous and open surgeries are contraindicated in these patients. ${ }^{109,110}$ This is because there is 20- to 40-fold increased risk of peri-renal hematomas and hemorrhagic complications in patients with uncorrected coagulopathies undergoing SWL when compared with patients with a normal bleeding profile. ${ }^{111,112}$ Therefore, in consultation with a haematologist or a cardiologist, bleeding coagulopathies need to be corrected and anticoagulation therapy appropriately withheld perioperatively. ${ }^{113}$ In addition, patients with increased risk of thromboembolic disease could be managed by bridging with subcutaneous low molecular weight heparin, while oral anticoagulation is held. ${ }^{114}$ In a retrospective series of 27 anti-coagulated patients who underwent PCNL with bridging, the stonefree rate was $93 \%$ while $7 \%$ developed significant bleeding and $4 \%$ had thromboembolic complications. ${ }^{115}$ The only prospective SWL study of patients on anti-platelet agents is that of Zanetti and colleagues. ${ }^{116}$ In this level 2b study, 23 patients were stratified to being at low-risk or at highrisk of thromboembolic events. Low-risk patients had their antiplatelet agents withheld for eight days prior to SWL, whereas high-risk patients received unfractionated heparin
5000 units thrice daily while anti-platelet agents were held. In both groups anti-platelet agents were re-started within 10 to 14 days of withdrawal and patients were followed with abdominal ultrasound and serial hemoglobin/hematocrit measurements. There were no hematomas or thromboembolic events in either group. ${ }^{116}$

Recent advances in manufacturing small-calibre ureteroscopes and introduction of Ho:YAG laser energy in lithotripsy have made it possible for patients with coagulopathies to safely undergo URS and laser lithotripsy while anticoagulated. ${ }^{10,117-119}$ However, this is associated with lower stone-free rates and increased risk of postoperative gross hematuria necessitating admission and bladder irrigation. ${ }^{111,120}$ Therefore, risks and benefits of withholding anticoagulation or proceeding with URS while anti-coagulated should be discussed with the patient and his/her cardiologist or hematologist.

Recommendations: SWL and PCNL are contraindicated in patients with uncorrected coagulopathies. When possible, coagulopathies should be corrected after consulting with a cardiologist and/or hematologist. However, when risks of withholding anti-coagulants outweigh the benefits, proceeding with URS and laser lithotripsy, while anti-coagulated, is an acceptable option (Level of Evidence 2b, Grade B).

\section{Urinary diversion}

Urinary diversions can be classified anatomically into abdominal (such as ileal conduits and catheterizable pouches), urethral (such as orthotopic neobladder) and ureterosigmoidostomy, with ileal conduit representing most (84\%) of cases. ${ }^{121,122}$

Patients with urinary diversions are at high risk of stone formation in light of numerous risk factors, including metabolic abnormalities (i.e., metabolic acidosis, hypocitraturia, hyperoxaluria and hypercalciuria), recurrent infections with urease-splitting organisms (e.g., Proteus), prolonged urinary stasis, prolonged exposure of urine to non-absorbable materials (e.g., staples), anatomical changes following diversion, and reflux of mucous into the upper tract. ${ }^{123}$

The reported incidence of upper tract calculi in patients with urinary diversion is $1 \%$ to $11 \%$ depending on the type of diversion, uretero-intestinal anastmosis and the follow-up period. The most common stone types are magnesium ammonium phosphate (struvite) and calcium phosphate stones. ${ }^{124}$

The established anatomical changes in these patients necessitate accurate preoperative assessment by CT scan to determine whether there are overlying bowel loops, especially if percutaneous access is contemplated. ${ }^{125}$ Ultrasoundguided access is recommended in these cases to avoid intervening bowel loops. ${ }^{126}$

Dealing with the stones in these patients represents a challenge to the urologist. Many factors need to be considered 
when choosing a certain approach. These factors include: stone size, location, patient performance status, availability of advanced SWL machines and flexible ureteroscopes with Ho:YAG laser lithotripsy, and finally, surgeon experience in dealing with these structural changes in the urinary tract. ${ }^{127}$ In addition, PCNL in these patients is associated with higher rates of postoperative fever or sepsis $(8 \%$ vs. $0 \%, p<0.05)$ and higher rates of second-look nephroscopy (36\% vs. $16 \%$, $p<0.05)$ compared to those with normal anatomy. ${ }^{126}$

Minimally invasive modalities, such as SWL, URS and $P C N L$, that produce the best stone-free rates should be used in these patients since these would avoid open surgical management and are associated with lower morbidity, early convalescence and shorter hospital stay. ${ }^{124}$ When performing antegrade URS for management of ureteral stones, a ureteral access sheath can be placed in an antegrade fashion to improve irrigation and facilitate access with a flexible ureteroscope. ${ }^{122}$

Close follow-up in these patients is mandatory because the risk of re-growth and recurrence is as high as $63 \%$ at the 5 -year follow-up. ${ }^{128}$ There are many important factors that may prevent or at least prolong the period before recurrence. These include increased fluid intake, timed voiding or frequent clean intermittent catheterization, and frequent irrigation of reservoirs. ${ }^{129}$ Metabolic workup to identify correctable risk factors, medical management of metabolic consequences of diversion, and long-term antibiotic prophylaxis against recurrent infections are also important to reduce recurrence. ${ }^{125}$

Also of importance, the urologist should consider the possibility of anastomotic stricture or recurrent malignancy when stones are lodged near the uretero-enteric anastomosis.

Recommendations: Ureteral calculi in patients with urinary diversions are challenging. While small, non-obstructive, asymptomatic stones could be managed conservatively, SWL could be attempted for obstructive stones (Level of Evidence 4, Grade C). If SWL fails, then retrograde URS with laser lithotripsy could be attempted if the ureteral orifice can be accessed (Fig. 1). However, the most effective modality for clearing large obstructive ureteral stones is percutaneously through antegrade URS (Level of Evidence 4, Grade C). It should be noted, however, that percutaneous renal surgery in patients with urinary diversion is associated with higher rates of postoperative sepsis and higher rates of second-look nephroscopy (Level of Evidence 2b, Grade B). When percutaneous procedures fail, ureterolithotomy is the last option in these patients (Level of Evidence 4, Grade C).

\section{Antegrade URS and ureterolithotomy}

In select circumstances, a percutaneous antegrade approach may be necessary instead of a retrograde endoscopic approach. As discussed above, prior urinary diversion represents one of these situations. Antegrade URS can also be considered a treatment option in the following situations: (1) in select cases with a large, impacted proximal ureteral stones; (2) when performed in conjunction with renal stone removal; (3) in select cases following failure of a retrograde ureteroscopic attempt for a large, impacted proximal ureteral stone; ${ }^{130}$ and (4) when the ureteral stone is in a transplant kidney. ${ }^{131}$

For large $(>15 \mathrm{~mm})$, impacted proximal ureteral stones, the stone-free rate with antegrade URS ranges between $98.5 \%$ and $100 \%$ with a low risk for complications. ${ }^{130,132-136}$

Laparoscopic, robotic or open ureterolithotomy may be considered when ureteroscopic and percutaneous procedures have failed or concomitant surgery is required. ${ }^{137}$

Recommendations: Percutaneous antegrade URS should be considered in the treatment of stones in patients with urinary diversion and select large, impacted proximal ureteral stones, especially when prior retrograde URS has failed (Level of Evidence 4, Grade C). Ureterolithotomy is a salvage option when endoscopic procedures have failed (Level of Evidence 2b, Grade B).

\section{Uric acid stones}

Uric acid (UA) urolithiasis is a multi-factorial disease. Persistently low 24-hour urinary $\mathrm{pH}(\leq 5.5)$ is regarded as the most important factor in formation of UA stones. UA stones constitute about $10 \%$ of urolithiasis in the general population, but this percentage increases up to $34 \%$ of stones in patients with metabolic syndrome and up to $52.2 \%$ of stones in patients with gout. ${ }^{138,139} \mathrm{UA}$ stones are typically radiolucent on plain radiographs and of low attenuation values $(<500 \mathrm{HU})$ on non-contrast CT scans of the abdomen. ${ }^{140}$ Recently, dual-energy CT scanning has been found to be superior to the conventional "single-energy" non-contrast CT scanning in differentiating non-uric acid stones from UA stones. ${ }^{141}$ However, dual-energy CT scans are not widely available.

Laboratory evaluation should include serum creatinine, potassium, uric acid, and when renal colic subsides, 24-hour urine collection should be obtained and checked for urine volume, urinary $\mathrm{pH}$ and uric acid excretion. ${ }^{142}$

When there are no signs of impending renal failure or sepsis, treatment of UA calculi depends primarily on increased water intake, reduction in the consumption of non-diary animal protein (low purine diet), and urinary alkalinisation using alkalinising agents, such as potassium citrate or sodium bicarbonate leading to stone dissolution. ${ }^{138,142-144}$ 


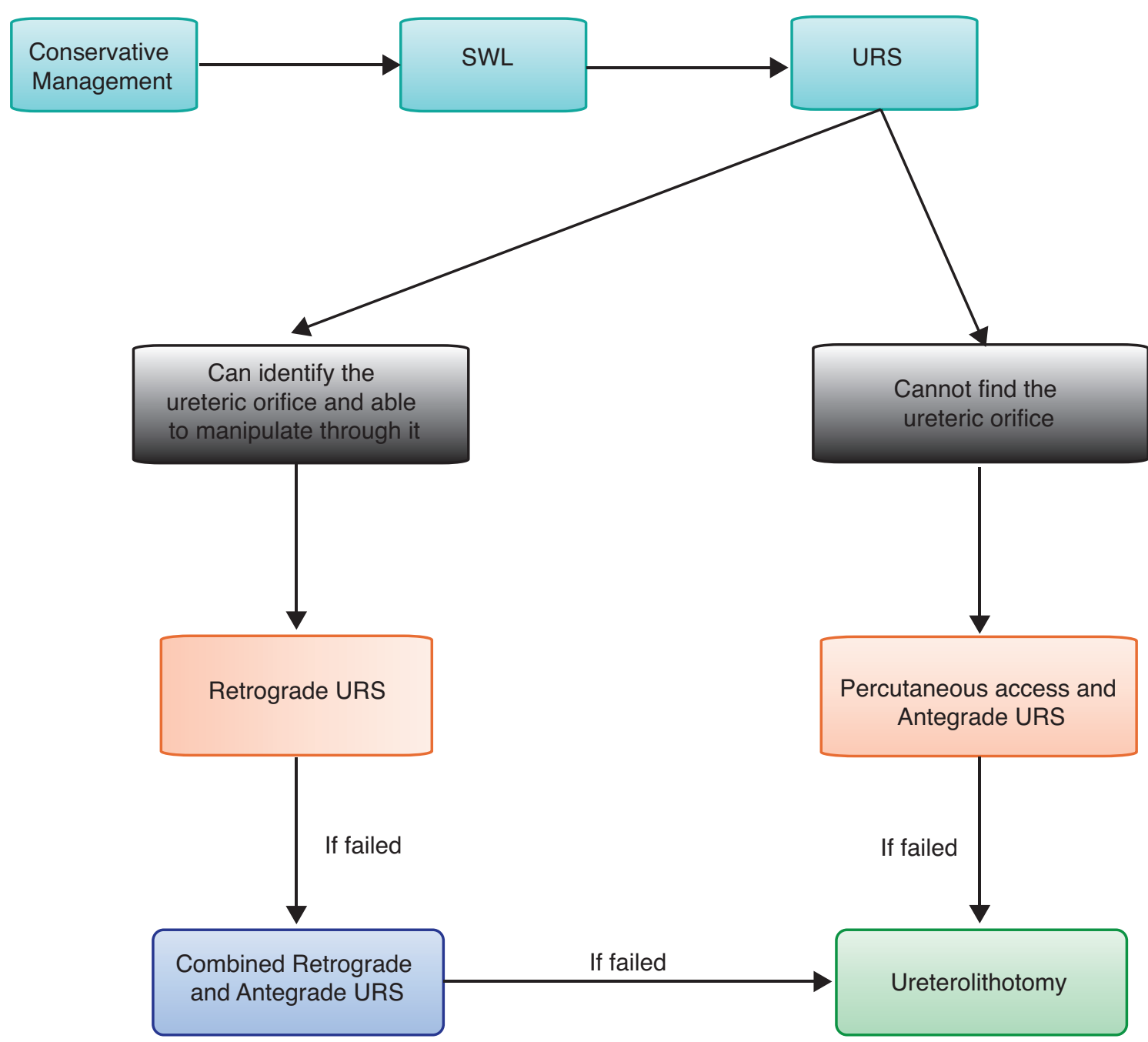

Fig. 1. Algorithm for approaching ureteral calculi in patients with urinary diversions.

When these agents are given to patients after ESWL or PCNL, they facilitate the dissolution of residual stones $<4 \mathrm{~mm}$ and prevent stone re-growth and recurrence. ${ }^{145}$ In addition, the combination of alpha blockers (such as tamsulosin) and potassium citrate have been associated with significantly higher stone-free rates when compared with either therapy alone or with placebo in patients with distal ureteric UA stones (84.4\%, 68.8\%, 58.7\%, and $26.1 \%$, respectively). ${ }^{146}$

Although UA stones are easy to fragment by SWL, they are difficult to localize due to their radiolucency. Contrast media injection, either through the intravenous route, retrograde ureteropyelography through a ureteral catheter, or antegrade administration through a nephrostomy tube, can be used to localize the radiolucent UA stones. The latest generation of lithotripters come equipped with ultrasonographic targeting, which could be used to localize UA stones. URS and laser lithotripsy are also very effective at treating UA stones in the ureter.

Recommendations: UA stones should be suspected when the stone is radiolucent on plain radiograph, the density is $<500 \mathrm{HU}$ on non-contrast CT scan, and it is associated with acidic urine $(\mathrm{pH} \leq 5.5)$ (Level of Evidence $2 b$, Grade B). Alkalinization with potassium/sodium citrate or sodium bicarbonate can be used in conjunction with medical expulsive therapy, such as tamsulosin, or endourologic procedures, such as SWL, URS or PCNL, to increase stone-free rates of UA stones (Level of Evidence 1b, Grade A). 
Infected obstructing ureteral stones

The basic tenet of treating any infected area or abscess is drainage followed by antibiotics. An obstructing ureteral stone in the setting of infection constitutes a requirement for urgent urologic treatment. Drainage of the obstructed renal unit is paramount and can be performed either by insertion of a ureteral stent or a percutaneous nephrostomy tube. It is generally agreed that definitive treatment of the obstructing stone should not be undertaken until the system has been drained, adequate antibiotics have been administered, and the infection treated. In the only prospective randomized trial, patients presenting with a fever $>38^{\circ} \mathrm{C}$, leukocytosis, and obstructing stone smaller than $15 \mathrm{~mm}$ were randomized to receive a ureteral stent or a nephrostomy tube insertion via interventional radiology. ${ }^{147}$ There was no difference in time to defervescence, hospital stay, resolution of obstruction, or overall clinical improvement. Others have also found no difference between decompression via nephrostomy or ureteral stent. ${ }^{148-150}$

The method of decompression should be tailored to each centre and its available resources. Placement of a nephrostomy tube is not on the list of core competencies for all radiologists and therefore may not be available at all centres. One survey found that only $44 \%$ of hospitals in the United Kingdom are capable of nephrostomy tube insertion. ${ }^{151}$ Ureteral stenting should be more widely available, but does require cystoscopy or an operating theatre setting, fluoroscopy or ultrasound, and trained staff. Broad spectrum antibiotics should be started early upon diagnosis; when starting within 1 hour of diagnosis, the survival rate is greater than $80 \%$ and each hour delay results in decreased survival ( $8 \%$ per hour). ${ }^{152}$

Recommendation: Obstructing ureteral stones resulting in urosepsis and infection require emergent drainage. The two methods of decompression, ureteral stenting or nephrostomy tube placement, are equivalent in outcomes and the method chosen will depend on availability of resources at each particular hospital. It is important to start broad-spectrum antibiotics early. Definitive stone treatment should be delayed until decompression and adequate antibiotics have been administered to treat the infection (Level of Evidence Level 2b, Grade B).

Competing interests: Dr. Ordon, Dr. Andonian, Dr. Schuler and Dr. Blew declare no competing financial or personal interests. Dr. Chew is a member of the Advisory Boards for Boston Scientific, Cook Medical, Olympus, Poly-Med, Advatec Inc., and PercSys Inc. He is also participating in clinical trials with Poly-Med Inc., and Advatec Inc. Dr. Pace is a member of the Advisory Board for Boston Scientific.

This paper has been peer-reviewed.

\section{References}

1. Matlaga BR, Lingeman JE. Surgical management of upper urinary tract calculi. In: Campbell-Walsh Urology. 10th ed. Edited by AJ Wein, LR Kavoussi, AC Novick, AW Partin, CA Peters. Philadelphia: PA, Elsevier Saunders; 2012:1357-410. http://dx.doi.org/10.1016/b978-1-4160-6911-9.00048-7

2. Miller OF, Kane CJ. Time to stone passage for observed ureteral calculi: A guide for patient education. J Urol 1999;162:688-91. http://dx.doi.org/10.1097/00005392-199909010-00014

3. Hubner WA, Irby P, Stoller ML. Natural history and current concepts for the treatment of small ureteral calculi. Eur Urol 1993;24:172.

4. Preminger GM, Tiselius HG, Assimos DG, et al. 2007 Guideline for the management of ureteral calculi. Eur Urol 2007;52:1610-31. http://dx.doi.org/10.1016/j.eururo.2007.09.039

5. Coll DM, Varanelli MJ, Smith RC. Relationship of spontaneous passage of ureteral calculi to stone size and location as revealed by unenhanced helical CT. AJR Am J Roentgenol 2002;178:101-3. http:// dx.doi.org/10.2214/ajr.178.1.1780101

6. Berkovitz N, Simanovsky N, Katz R, et al. Coronal reconstruction of unenhanced abdominal CT for correct ureteral stone size classification. Eur Radiol 2010;20:1047-51. http://dx.doi.org/10.1007/ s00330-009-1636-7

7. Ray AA, Ghiculete D, Pace KT, et al. Limitations to ultrasound in the detection and measurement of urinary tract calculi. Urology 2010;76:295-300. http://dx.doi.org/10.1016/j.urology.2009.12.015

8. Campschroer T, Zhu Y, Duijvesz D, et al. Alpha-blockers as medical expulsive therapy for ureteral stones. Cochrane Database Syst Rev 2014;4:CD008509. http://dx.doi.org/10.1002/14651858.cd008509. pub2

9. Pickard R, Starr K, MacLennan G, et al. Medical expulsive therapy in adults with ureteric colic: A multicentre, randomised, placebo-controlled trial. Lancet 2015; http://dx.doi.org/10.1016/S01406736(15)60933-3

10. Aboumarzouk OM, Kata SG, Keeley FX, et al. Extracorporeal shock wave lithotripsy (ESWL) versus ureteroscopic management for ureteric calculi. Cochrane Database Syst Rev 2012;5:CD006029. http:// dx.doi.org/10.1002/14651858.cd006029.pub4

11. Matlaga BR, Jansen JP, Meckley LM, et al. Treatment of ureteral and renal stones: A systematic review and meta-analysis of randomized, controlled trials. J Urol 2012;188:130-7. http://dx.doi.org/10.1016/i. juro.2012.02.2569

12. Saw KC, Lingeman JE. Lesson 20: Management of Calyceal Stones, 1999;154-59.

13. Lee $\Pi$, Elkoushy MA, Andonian S. Are stone analysis results different with repeated sampling? Can Urol Assoc J 2014;8:E317-22. http://dx.doi.org/10.5489/cuaj.1872

14. Matlaga BR, Kawamoto S, Fishman E. Dual source computed tomography: A novel technique to determine stone composition. Urology 2008;72:1164-8. http://dx.doi.org/10.1016/i.urology.2008.03.051

15. Boll DT, Patil NA, Paulson EK, et al. Renal stone assessment with dual-energy multidetector CT and advanced postprocessing techniques: Improved characterization of renal stone composition-pilot study. Radiology 2009;250:813. http://dx.doi.org/10.1148/radiol.2503080545

16. Gupta NP, Ansari MS, Kesarvani P, et al. Role of computed tomography with no contrast medium enhancement in predicting the outcome of extracorporeal shock wave lithotripsy for urinary calculi. BJU Int 2005;95:1285-8. http://dx.doi.org/10.1111/j.1464-410X.2005.05520.x

17. Joseph P, Mandal AK, Singh SK, et al. Computerized tomography attenuation value of renal calculus: Can it predict successful fragmentation of the calculus by extracorporeal shock wave lithotripsy? A preliminary study. J Urol 2002;167:1968-71. http://dx.doi.org/10.1016/S0022-5347(05)65064-1

18. El-Nahas AR, El-Assmy AM, Mansour 0 , et al. A prospective multivariate analysis of factors predicting stone disintegration by extracorporeal shock wave lithotripsy: The value of high-resolution noncontrast computed tomography. Eur Urol 2007:51:1688-94. http://dx.doi.org/10.1016/i.eururo.2006.11.048

19. Ouzaid I, Al-qahtani S, Dominique S, et al. A 970 Hounsfield units (HU) threshold of kidney stone density on non-contrast computed tomography (NCCT) improves patients' selection for extracorporeal shockwave lithotripsy (ESWL): Evidence from a prospective study. BJU Int 2012;110:E438-42. http://dx.doi. org/10.1111/i.1464-410X.2012.10964.x

20. Wiesenthal JD, Ghiculete D, Ray AA, et al. A clinical nomogram to predict the successful shock wave lithotripsy of renal and ureteral calculi. J Urol 2011;186:556-62. http://dx.doi.org/10.1016/i. juro.2011.03.109

21. Patel $\mathrm{T}$, Kozakowski K, Hruby $G$, et al. Skin to stone distance is an independent predictor of stone-free status following shockwave lithotripsy. J Endourol 2009;23:1383.

22. Pishchalnikov YA, Neucks IS, VonDerHaar RJ, et al. Air pockets trapped during routine coupling in dry head lithotripsy can significantly decrease the delivery of shock wave energy. J Urol 2006;176:2706.

23. Jain A, Shah TK. Effect of air bubbles in the coupling medium on efficacy of extracorporeal shock wave lithotripsy. Eur Urol 2007;51:1680

24. Neucks JS, Pishchalnikov YA, Zancanaro AJ, et al. Improved acoustic coupling for shock wave lithotripsy. Urol Res 2008;36:61. 
25. Bergsdorf T, Chaussy C, Thüroff S. Energy coupling in extracorporeal shock wave lithotripsy—-the impact of coupling quality on disintegration efficacy. J Endourol 2008;22:A161.

26. Bohris C. Quality of coupling in ESWL significantly affects the disintegration capacity — how to achieve good coupling with ultra-sound gel. In: Therapeutic energy applications in urology II: standards and recent developments. Eds: Chaussy, G. Haupt, D. Jocham et al. Stuttgart, Germany: Thieme; 2010:61-4.

27. Bohris C, Bayer T, Gumpinger R. Ultrasound monitoring of kidney stone extracorporeal shockwave lithotripsy with an external transducer: Does fatty tissue cause image distortions that affect stone comminution? J Endourol 2010;24:81-8. http://dx.doi.org/10.1089/end.2009.0158

28. Cleveland RO, Anglade R, Babayan RK. Effect of stone motion on in vitro comminution efficiency of Storz Modulith SLX. J Endourol 2004;18:629-33. http://dx.doi.org/10.1089/end.2004.18.629

29. Logarakis NF, Jewett MA, Luymes J, et al. Variation in clinical outcome following shock wave lithotripsy. J Urol 2000;163:721-5. http://dx.doi.org/10.1016/S0022-5347(05)67791-9

30. Hartung A, Schwarze W. LithoSpace by AST GmbH. In: Therapeutic energy applications in urology II: standards and recent developments. Edited by C. Chaussy, G. Haupt, D. Jocham et al. Stuttgart, Germany Thieme; 2010:53-6.

31. McAteer JA, Evan AP, Williams JC Jr, et al. Treatment protocols to reduce renal injury during shock wave lithotripsy. Curr Opin Urol 2009;19:192-5. http://dx.doi.org/10.1097/MOU.0b013e32831el6e3

32. Lambert EH, Walsh R, Moreno MW, et al. Effect of escalating versus fixed voltage treatment on stone comminution and renal injury during extracorporeal shock wave lithotripsy: A prospective randomized trial. J Urol 2010;183:580-4. http://dx.doi.org/10.1016/i.juro.2009.10.025

33. Willis LR, Evan AP, Connors BA, et al. Prevention of lithotripsy-induced renal injury by pretreating kidneys with low-energy shock waves. J Am Soc Nephrol 2006;17:663-73. http://dx.doi.org/10.1681/ ASN.2005060634

34. Weizer AZ, Zhong P, Preminger GM. New concepts in shock wave lithotripsy. Urol Clin North Am 2007;34:375-82. http://dx.doi.org/10.1016/i.ucl.2007.07.002

35. Seemann 0, Rassweiler J, Chvapil $M$, et al. The effect of single shock waves on the vascular system of artificially perfused rabbit kidneys. I Stone Dis 1993;5:172

36. Pace KT, Weir MJ, Tariq N, et al. Low success rate of repeat shock wave lithotripsy for ureteral stones after failed initial treatment. J Urol 2000;164:1905. http://dx.doi.org/10.1016/S0022-5347(05)66914-5

37. Rassweiler JJ, Knoll T, Kohrmann KU, et al. Shock wave technology and application: An update. Eur Urol 2011:59:784-96. htrp://dx.doi.org/10.1016/i.eururo.2011.02.033

38. Pace KT, Ghiculete D, Hariu M, et al. Shock wave lithotripsy at 60 or 120 shocks per minute: A randomized, double-blind trial. J Urol 2005;174:595-9. http://dx.doi.org/10.1097/01.ju.0000165156.90011.95

39. Honey RJ, Schuler TD, Ghiculete D, et al. A randomized, double-blind trial to compare shock wave frequencies of 60 and 120 shocks per minute for upper ureteral stones. J Urol 2009;182:1418-23. http:// dx.doi.org/10.1016/i.juro.2009.06.019

40. Davenport K, Minervini A, Keoghane S, et al. Does rate matter? The results of a randomized controlled tria of 60 versus 120 shocks per minute for shock wave lithotripsy of renal calculi. J Urol 2006;176:2055-8. http://dx.doi.org/10.1016/i.juro.2006.07.012

41. Madbouly K, El-Tiraifi AM, Seida M, et al. Slow versus fast shock wave lithotripsy rate for urolithiasis: A prospective randomized study. J Urol 2005;173:127-30. http://dx.doi.org/10.1097/01. ju.0000147820.36996.86

42. Yilmaz E, Batislam E, Basar M, et al. Optimal frequency in extracorporeal shock wave lithotripsy: Prospective randomized study. Urology 2005;66:1160-4. http://dx.doi.org/10.1016/i.urology.2005.06.111

43. Li K, Lin T, Zhang C, et al. Optimal frequency of shock wave lithotripsy in urolithiasis treatment: A systematic review and meta-analysis of randomized controlled trials. J Urol 2013;190:1260-7. http:// dx.doi.org/10.1016/i.juro.2013.03.075

44. Kato $Y$, Yamaguchi $S$, Hori J, et al. Improvement of stone comminution by slow delivery rate of shock waves in extracorporeal lithotripsy. Int I Urol 2006;13:1461-5. http://dx.doi.org/10.1111/j.14422042.2006.01609.x

45. Chacko J, Moore M, Sankey N, et al. Does a slower treatment rate impact the efficacy of extracorporeal shock wave lithotripsy for solitary kidney or ureteral stones? J Urol 2006;175:1370-4. http://dx.doi. org/10.1016/S0022-5347(05)00683-X

46. Schuler TD, Shahani R, Honey RJ, et al. Medical expulsive therapy as an adjunct to improve shockwave lithotripsy outcomes: A systematic review and meta-analysis. J Endourol 2009;23:387-93. http://dx.doi. org/10.1089/end.2008.0216

47. Bhagat SK, Chacko NK, Kekre NS, et al. Is there a role for tamsulosin in shock wave lithotripsy for renal and ureteral calculi? J Urol 2007;177:2185-8. http://dx.doi.org/10.1016/i.juro.2007.01.160

48. Gravina GL, Costa AM, Ronchi P, et al. Tamsulosin treatment increases clinical success rate of single extracorporeal shock wave lithotripsy of renal stones. Urology 2005;66:24-8. hittp://dx.doi.org/10.1016/i. urology.2005.01.013

49. Porpigia F, Destefanis $P$, Fiori $C$, et al. Role of adjunctive medical therapy with nifedipine and deflazacort after extracorporeal shock wave lithotripsy of ureteral stones. Urology 2002;59:835-8. http://dx.doi. org/10.1016/50090-4295(02)01553-4
50. Micali S, Sighinolfi MC, Celia A, et al. Can Phyllanthus niruri affect the efficacy of extracorporeal shock wave lithotripsy for renal stones? A randomized, prospective, long-term study. J Urol 2006; 176:1020-2. http://dx.doi.org/10.1016/i.juro.2006.04.010

51. Zhu Y, Duijvesz D, Rovers MM, et al. Alpha-nlockers to assist stone clearance after extracorporeal shock wave lithotripsy: A meta-analysis. BJU Int 2010;106:256-61. http://dx.doi.org/10.1111/i.1464410X.2009.09014.X

52. Gravas S, Tzortzis V, Karatzas A, et al. The use of tamsulozin as adjunctive treatment after ESWL in patients with distal ureteral stone: Do we really need it? Results from a randomised study. Urol Res 2007;35:231-5. http://dx.doi.org/10.1007/s00240-007-0106-4

53. Kupeli $B$, Irkilata $L$, Gurocak $S$, et al. Does tamsulosin enhance lower ureteral stone clearance with or without shock wave lithotripsy? Urology 2004;64:1111-5. http://dx.doi.org/10.1016/j.urology.2004.07.020

54. Micali S, Grande M, Sighinolfi MC, et al. Efficacy of expulsive therapy using nifedipine or tamsulosin, both associated with ketoprofene, after shock wave lithotripsy of ureteral stones. Urol Res 2007;35:133-7. http://dx.doi.org/10.1007/s00240-007-0085-5

55. Naja V, Agarwal MM, Mandal AK, et al. Tamsulosin facilitates earlier clearance of stone fragments and reduces pain after shockwave lithotripsy for renal calculi: Results from an open-label randomized study. Urology 2008;72:1006-11. hitp://dx.doi.org/10.1016/i.urology.2008.05.035

56. Kobayashi $M$, Naya $Y$, Kino $M$, et al. Low dose tamsulosin for stone expulsion after extracorporeal shock wave lithotripsy: Efficacy in Japanese male patients with ureteral stone. Int I Urol 2008;15:495-8. http://dx.doi.org/10.1111/i.1442-2042.2008.02033.x

57. Wang HJ, Liu K, Ji ZG, et al. Application of Alphal-adrenergic antagonist with extracorporeal shock wave lithotripsy for lower ureteral stone [in Chinese]. Zhongguo Yi Xue Ke Xue Yuan Xue Bao 2008;30:506.

58. Musa AA. Use of double-J stents prior to extracorporeal shock wave lithotripsy is not beneficial: Results of a prospective randomized study. Int Urol Nephrol 2008;40:19-22. http://dx.doi.org/10.1007/ s1 1255-006-9030-8

59. Pettenati C, El Fegoun AB, Hupertan V, et al. Double I stent reduces the efficacy of extracorporeal shock wave lithotripsy in the treatment of lumbar ureteral stones. Cent European J Urol 2013;66:309. http:// dx.doi.org/10.5173/ceju.2013.03.art14

60. Sfoungaristos $S$, Polimeros N, Kavouras, A. et al. Stenting or not prior to extracorporeal shockwave lithotripsy for ureteral stones? Results of a prospective randomized study. Int Urol Nephrol 2012;44:731-7. http://dx.doi.org/10.1007/s1 1255-011-0062-3

61. Argyropoulos AN, Tolley DA. Ureteric stents compromise stone clearance after shockwave lithotripsy for ureteric stones: Results of a matched-pair analysis. BJU Int 2009;103:76-80. http://dx.doi. org/10.1111/i.1464-410X.2008.07886.x

62. Lucio I 2nd, Korkes F, Lopes-Neto AC, et al. Steinstrasse predictive factors and outcomes after extracorporeal shockwave lithotripsy. Int Braz J Urol 2011;37:477. http://dx.doi.org/10.1590/S167755382011000400006

63. Mustafa M, Ali-El-Dein B. Stenting in extracorporeal shockwave lithotripsy may enhance the passage of the fragments. J Pak Med Assoc 2009;59:141.

64. Duvdevani $M$, Lorber $G$, Gofrit $O N$, et al. Fever after shockwave lithotripsy-risk factors and indications for prophylactic antimicrobial treatment. J Endourol 2010;24:277-81. http://dx.doi.org/10.1089/ end.2009.0283

65. Bapat SS, Pai KV, Purnapatre SS, et al. Comparison of holmium laser and pneumatic lithotripsy in managing upper-ureteral stones. J Endourol 2007;21:1425-8. http://dx.doi.org/10.1089/end.2006.0350

66. Binbay $M$, Tepeler A, Singh A, et al. Evaluation of pneumatic versus holmium:YAG laser lithotripsy for impacted ureteral stones. Int Urol Nephrol 2011;43:989-95. http://dx.doi.org/10.1007/s11255011-9951-8

67. Maghsoudi R, Amiadi M, Norizadeh D, et al. Treatment of ureteral stones: A prospective randomized controlled trial on comparison of Ho:YAG laser and pneumatic lithotripsy. Indian J Urol 2008;24:352-4. http://dx.doi.org/10.4103/0970-1591.39549

68. Demir A, Karadag MA, Cecen K, et al. Pneumatic versus laser ureteroscopic lithotripsy: A comparison of initial outcomes and cost. Int Urol Nephrol 2014;46:2087-93. http://dx.doi.org/10.1007/s11255014-0787-x

69. Atar $M$, Bodakci MN, Sancaktutar AA, et al. Comparison of pneumatic and laser lithotripsy in the treatment of pediatric ureteral stones. J Pediatr Urol 2013;9:308-12. http://dx.doi.org/10.1016/i. jpurol.2012.03.004

70. Teichman JM, Rao RD, Rogenes VJ, et al. Ureteroscopic management of ureteral calculi: Electrohydraulic versus holmium:YAG lithotripsy. J Urol 1997;158:1357-61. http://dx.doi.org/10.1016/S0022$5347(01) 64214-9$

71. Rehman J, Monga $M$, Landman J, et al. Characterization of intrapelvic pressure during ureteropyeloscopy with ureteral access sheaths. Urology 2003;61:713-8. http://dx.doi.org/10.1016/S00904295(02)02440-8 
Ordon et al.

72. Auge $B K$, Pietrow PK, Lallas $C D$, et al. Ureteral access sheath provides protection against elevated renal pressures during routine flexible ureteroscopic stone manipulation. J Endourol 2004;18:33-6. http:// dx.doi.org/10.1089/089277904322836631

73. Kourambas J, Byrne RR, Preminger GM. Does a ureteral access sheath facilitate ureteroscopy? J Urol 2001;165:789-93. http://dx.doi.org/10.1016/S0022-5347(05)66527-5

74. L'Esperance J0, Ekeruo W0, Scales CD Jr, et al. Effect of ureteral access sheath on stone-free rates in patients undergoing ureteroscopic management of renal calculi. Urology 2005;66:252-6. http://dx.doi. org/10.1016/i.urology.2005.03.019

75. Berquet $G$, Prunel $P$, Verhoest $G$, et al. The use of a ureteral access sheath does not improve stone-free rate after ureteroscopy for upper urinary tract stones. World J Urol 2014;32:229-32. http://dx.doi. org/10.1007/s00345-013-1181-5

76. Lallas $C D$, Auge BK, Raj GV, et al. Laser Doppler flowmetric determination of ureteral blood flow after ureteral access sheath placement. J Endourol 2002;16:583-90. http://dx.doi. org $/ 10.1089 / 089277902320913288$

77. Traxer 0 , Thomas $A$. Prospective evaluation and classification of ureteral wall injuries resulting from insertion of a ureteral access sheath during retrograde intrarenal surgery. J Urol 2013;189:580-4. http://dx.doi. org/10.1016/i.juro.2012.08.197

78. Yaycioglu 0 , Guvel $S$, Kilinc $F$, et al. Results with $7.5 \mathrm{~F}$ versus $10 \mathrm{~F}$ rigid ureteroscopes in treatment of ureteral calculi. Urology 2004;64:643-6. http://dx.doi.org/10.1016/i.urology.2004.05.050

79. Atis $G$, Arikan 0 , Gurbuz $C$, et al. Comparison of different ureteroscope sizes in treating ureteral calculi in adult patients. Urology 2013;82:1231-5. http://dx.doi.org/10.1016/i.urology.2013.07.021

80. Hudson RG, Conlin MJ, Bagley DH. Ureteric access with flexible ureteroscopes: Effect of the size of the ureteroscope. BJU Int 2005;95:1043-4. http://dx.doi.org/10.1111/i.1464-410X.2005.05462.x

81. Bach C, Nesar $S$, Kumar $P$, et al. The new digital flexible ureteroscopes: 'size does matter'-increased ureteric access sheath use! Urol Int 2012;89:408-11. http://dx.doi.org/10.1159/000341429

82. Somani BK, Al-Qahtani SM, de Medina SD, et al. Outcomes of flexible ureterorenoscopy and laser fragmentation for renal stones: Comparison between digital and conventional ureteroscope. Urology 2013;82:1017-9. http://dx.doi.org/10.1016/i.urology.2013.07.017

83. Binbay $M$, Yuruk $E$, Akman $T$, et al. Is there a difference in outcomes between digital and fiberoptic flexible ureterorenoscopy procedures? J Endourol 1929;24:1929-34. http://dx.doi.org/10.1089/ end.2010.0211

84. Chu L, Farris CA, Corcoran AT, et al. Preoperative stent placement decreases cost of ureteroscopy. Urology 2011;78:309-13. http://dx.doi.org/10.1016/i.urology.2011.03.055

85. Netsch C, Knipper S, Bach T, et al. Impact of preoperative ureteral stenting on stone-free rates of ureteroscopy for nephroureterolithiasis: A matched-paired analysis of 286 patients. Urology 2012;80:1214-20. http://dx.doi.org/10.1016/j.urology.2012.06.064

86. Bourdoumis A, Tanabalan C, Goyal A, et al. The difficult ureter: stent and come back or balloon dilate and proceed with ureteroscopy? What does the evidence say? Urology 2014;83:1-3. http://dx.doi. org/10.1016/i.urology.2013.08.073

87. Cetti RJ, Biers, S, Keoghane SR. The difficult ureter: What is the incidence of pre-stenting? Ann R Coll Surg Engl 2011;93:31-3. http://dx.doi.org/10.1308/003588411X12851639106990

88. Ambani SN, Faerber GJ, Roberts WW, et al. Ureteral stents for impassable ureteroscopy. J Endourol 2013;27:549-53. http://dx.doi.org/10.1089/end.2012.0414

89. Hosking DH, McColm SE, Smith WE. Is stenting following ureteroscopy for removal of distal ureteral calculi necessary? J Urol 1999;161:48-50. http://dx.doi.org/10.1016/S0022-5347(01)62058-5

90. Denstedt JD, Wollin TA, Sofer $M$, et al. A prospective randomized controlled trial comparing nonstented versus stented ureteroscopic lithotripsy. J Urol 2001;165:1419-22. http://dx.doi.org/10.1016/ S0022-5347(05)66320-3

91. Makarov DV, Trock BJ, Allaf ME, et al. The effect of ureteral stent placement on post-ureteroscopy complications: A meta-analysis. Urology 2008;71:796-800. http://dx.doi.org/10.1016/j.urology.2007.10.073

92. Pengfei $S$, Yutao $L$, Jie $Y$, et al. The results of ureteral stenting after ureteroscopic lithotripsy for ureteral calculi: A systematic review and meta-analysis. J Urol 2011;186:1904-9. http://dx.doi.org/10.1016/i juro.2011.06.066

93. Baseskioglu B, Sofikerim $M$, Demirtas $A$, et al. Is ureteral stenting really necessary after ureteroscopic lithotripsy with balloon dilatation of ureteral orifice? A multi-institutional randomized controlled study. World J Urol 2011;29:731-6. http://dx.doi.org/10.1007/s00345-011-0697-9

94. Cevik I, Dillioglugil 0 , Akdas A, et al. Is stent placement necessary after uncomplicated ureteroscopy for removal of impacted ureteral stones? J Endourol 2010;24:1263-7. http://dx.doi.org/10.1089/ end.2009.0153

95. Torricelli FC, De S, Hinck B, et al. Flexible ureteroscopy with a ureteral access sheath: When to stent? Urology 2014;83:278-81. http://dx.doi.org/10.1016/i.urology.2013.10.002

96. Rapoport D, Perks AE, Teichman JM. Ureteral access sheath use and stenting in ureteroscopy: Effect on unplanned emergency room visits and cost. J Endourol 2007;21:993-8. http://dx.doi.org/10.1089/ end.2006.0236
97. Shigemura K, Yasufuku T, Yamanaka K, et al. How long should double J stent be kept in after ureteroscopic lithotripsy? Urol Res 2012;40:373-6. http://dx.doi.org/10.1007/s00240-011-0426-2

98. White WM, Johnson EB, Zite NB, et al. Predictive value of current imaging modalities for the detection of urolithiasis during pregnancy: A multicenter, longitudinal study. J Urol 2013;189:931-4. http://dx.doi. org/10.1016/i.juro.2012.09.076

99. Masselli $G$, Derme $M$, Laghi $F$, et al. Imaging of stone disease in pregnancy. Abdom Imaging 2013;38:1409-14. http://dx.doi.org/10.1007/s00261-013-0019-3

100. Mullins JK, Semins MJ, Hyams ES, et al. Half Fourier single-shot turbo spin-echo magnetic resonance urography for the evaluation of suspected renal colic in pregnancy. Urology 2012;79:1252-5. http:// dx.doi.org/10.1016/j.urology.2011.12.016

101. Semins MJ, Matlaga BR. Management of stone disease in pregnancy. Curr Opin Urol 2010;20:174-7. hitp://dx.doi.org/10.1097/MOU.0b013e3283353a4b

102. Isen K, Hatipoglu NK, Dedeoglu S, et al. Experience with the diagnosis and management of symptomatic ureteric stones during pregnancy. Urology 2012;79:508-12. http://dx.doi.org/10.1016/i. urology.2011.10.023

103. Semins MJ, Matlaga BR. Kidney stones during pregnancy. Nat Rev Urol 2014;11:163-8. http://dx.doi. org/10.1038/nrurol.2014.17

104. Akpinar H, Tufek I, Alici B, et al. Ureteroscopy and holmium laser lithotripsy in pregnancy: Stents must be used postoperatively. J Endourol 2006;20:107-10. http://dx.doi.org/10.1089/end.2006.20.107

105. Watterson JD, Girvan AR, Beiko DT, et al. Ureteroscopy and holmium:YAG laser lithotripsy: An emerging definitive management strategy for symptomatic ureteral calculi in pregnancy. Urology 2002;60:383-7. http://dx.doi.org/10.1016/S0090-4295(02)01751-X

106. Bozkurt Y, Penbegul N, Soylemez $\mathrm{H}$, et al. The efficacy and safety of ureteroscopy for ureteral calculi in pregnancy: Our experience in 32 patients. Urol Res 2012;40:531. http://dx.doi.org/10.1007/ s00240-011-0454-y

107. Cocuzza M, Colombo JR Jr, Lopes Rl, et al. Use of inverted fluoroscope's C-arm during endoscopic treatment of urinary tract obstruction in pregnancy: A practicable solution to cut radiation. Urology 2010;75:1505-8. http://dx.doi.org/10.1016/i.urology.2009.12.014

108. Frankenschmidt A, Sommerkamp H. Shock wave lithotripsy during pregnancy: A successful clinical experiment. J Urol 1998;159:501-2. http://dx.doi.org/10.1016/S0022-5347(01)63962-4

109. Alsaikhan B, Andonian $S$. Shock wave lithotripsy in patients requiring anticoagulation or antiplatelet agents. Can Urol Assoc J 2011;5:53.

110. Aboumarzouk OM, Somani BK, Monga M. Flexible ureteroscopy and holmium:YAG laser lithotripsy for stone disease in patients with bleeding diathesis: A systematic review of the literature. Int Braz J Urol 2012;38:298

111. Klingler HC, Kramer G, Lodde M, et al. Stone treatment and coagulopathy. Eur Urol 2003;43:75.

112. Razvi H, Fuller A, Nott L, et al. Risk factors for perinephric hematoma formation after shockwave lithotripsy: A matched case-control analysis. J Endourol 2012;26:1478-82. http://dx.doi.org/10.1089/ end.2012.026

113. Tsuboi T, Fuijta T, Maru N, et al. Transurethral ureterolithotripsy and extracorporeal shock wave lithotripsy in patients with idiopathic thrombocytopenic purpura. Hinyokika Kiyo 2008;54:17

114. Kaatz S, Paje D. Update in bridging anticoagulation. J Thromb Thrombolysis 2011;31:259-64. http:// dx.doi.org/10.1007/s1 1239-011-0571-z

115. Kefer JC, Turna B, Stein RJ, et al. Safety and efficacy of percutaneous nephrostolithotomy in patients on anticoagulant therapy. J Urol 2009;181:144-8. http://dx.doi.org/10.1016/i.juro.2008.09.008

116. Zanetti G, Kartalas-Goumas I, Montanari E, et al. Extracorporeal shockwave lithotripsy in patients treated with antithrombotic agents. J Endourol 2001;15:237-41. http://dx.doi. org/10.1089/089277901750161656

117. Kuo RL, Aslan P, Fitzgerald KB, et al. Use of ureteroscopy and holmium:YAG laser in patients with bleeding diatheses. Urology 1998;52:609-13. http://dx.doi.org/10.1016/S0090-4295(98)00276-3

118. Watterson JD, Girvan AR, Cook AJ, et al. Safety and efficacy of holmium:YAG laser lithotripsy in patients with bleeding diatheses. J Urol 2002;168:442-5. http://dx.doi.org/10.1016/S0022-5347(05)64654-X

119. Turna B, Stein RJ, Smaldone MC, et al. Safety and efficacy of flexible ureterorenoscopy and holmium:YAG lithotripsy for intrarenal stones in anticoagulated cases. J Urol 2008;179:1415-9. http://dx.doi. org/10.1016/i.juro.2007.11.076

120. Elkoushy MA, Violette PD, Andonian S. Ureteroscopy in patients with coagulopathies is associated with lower stone-free rate and increased risk of clinically significant hematuria. Int Braz I Urol 2012;38:195. http://dx.doi.org/10.1590/S1677-55382012000200007

121. Mottet N, Castagnola C, Rischmann P, et al. Quality of life after cystectomy: French national survey conducted by the French Association of Urology (AFU), the French Federation of Stoma Patients (FSF) and the French Association of Enterostomy Patients (AFET) in patients with ileal conduit urinary diversion or orthotopic neobladder [in French]. Prog Urol 2008;18:292. 
122. Stuurman RE, Al-Qahtani SM, Cornu JN, et al. Antegrade percutaneous flexible endoscopic approach for the management of urinary diversion-associated complications. J Endourol 2013;27:1330-4. http:// dx.doi.org/10.1089/end.2012.0371

123. Dhar NB, Hernandez AV, Reinhardt $K$, et al. Prevalence of nephrolithiasis in patients with ileal bladder substitutes. Urology 2008;71:128-30. http://dx.doi.org/10.1016/i.urology.2007.08.058

124. El-Nahas AR, Shokeir AA. Endourological treatment of nonmalignant upper urinary tract complications after urinary diversion. Urology 2010;76:1302-8. http://dx.doi.org/10.1016/j.urology.2010.03.014

125. Okhunov Z, Duty B, Smith AD, et al. Management of urolithiasis in patients after urinary diversions. BJU Int 2011;108:330-6. http://dx.doi.org/10.1111/i.1464-410X.2011.10194.x

126. Fernandez A, Foell $K$, Nott $L$, et al. Percutaneous nephrolithotripsy in patients with urinary diversions: A case-control comparison of perioperative outcomes. J Endourol 2011;25:1615-8. http://dx.doi. org/10.1089/end.2011.0045

127. L'Esperance J0, Sung J, Marguet C, et al. The surgical management of stones in patients with urinary diversions. Curr Opin Urol 2004;14:129-34. http://dx.doi.org/10.1097/00042307-200403000-00014

128. Cohen TD, Streem SB, Lammert G. Long-term incidence and risks for recurrent stones following contemporary management of upper tract calculi in patients with a urinary diversion. J Urol 1996; 155:62-5. http:// dx.doi.org/10.1016/S0022-5347(01)66540-6

129. Hensle TW, Bingham J, Lam J, et al. Preventing reservoir calculi after augmentation cystoplasty and continent urinary diversion: the influence of an irrigation protocol. BJU Int 2004;93:585-7. http:// dx.doi.org/10.1111/j.1464-410X.2003.04664.x

130. Kumar V, Ahlawat R, Banjeree GK, et al. Percutaneous ureterolitholapaxy: The best bet to clear large bulk impacted upper ureteral calculi. Archivos espanoles de urologia 1996;49:86.

131. Rhee BK, Bretan PN Jr, Stoller ML. Urolithiasis in renal and combined pancreas/renal transplant recipients. J Urol 1999;161:1458-62. http://dx.doi.org/10.1016/S0022-5347(05)68926-4

132. Maheshwari PN, Oswal AT, Andankar $M$, et al. Is antegrade ureteroscopy better than retrograde ureteroscopy for impacted large upper ureteral calculi? J Endourol 1999;13:441.

133. Goel R, Aron M, Kesarwani PK, et al. Percutaneous antegrade removal of impacted upper-ureteral calculi: still the treatment of choice in developing countries. J Endourol 2005; 19:54.

134. Karami H, Arbab AH, Hosseini SJ, et al. Impacted upper-ureteral calculi $>1 \mathrm{~cm}$ : Blind access and totally tubeless percutaneous antegrade removal or retrograde approach? J Endourol 2006;20:616.

135. Topaloglu H, Karakoyunlu N, Sari S, et al. A comparison of antegrade percutaneous and laparoscopic approaches in the treatment of proximal ureteral stones. Biomed Res Int 2014;691946; http://dx.doi. org/10.1155/2014/691946

136. Zhu $\mathrm{H}, \mathrm{Ye}_{\mathrm{X}}$, Xiao X, et al. Retrograde, antegrade, and laparoscopic approaches to the management of large upper ureteral stones after shockwave lithotripsy failure: A four-year retrospective study. J Endourol 2014;28:100-3. http://dx.doi.org/10.1089/end.2013.0391

137. Lopes Neto AC, Korkes F, Silva JL 2nd, et al. Prospective randomized study of treatment of large proximal ureteral stones: Extracorporeal shock wave lithotripsy versus ureterolithotripsy versus laparoscopy. J Urol 2012;187:164-8. http://dx.doi.org/10.1016/i.juro.2011.09.054
138. Maalouf NM. Metabolic syndrome and the genesis of uric acid stones. J Ren Nutr 2011;21:128-31. http://dx.doi.org/10.1053/i.jrn.2010.10.015

139. Marchini GS, Sarkissian C, Tian D, et al. Gout, stone composition and urinary stone risk: A matched case comparative study. J Urol 2013;189:1334. http://dx.doi.org/10.1016/i.juro.2012.09.102

140. Ciudin ALP, Diaconu MG. Predicting urinary stone composition: A radiological study made by urologists. Eur Urol 2013;12:e436. http://dx.doi.org/10.1016/S1569-9056(13)60920-3

141. Wisenbaugh ES, Paden RG, Silva AC, et al. Dual-energy vs conventional computed tomography in determining stone composition. Urology 2014;83:1243-7. http://dx.doi.org/10.1016/i.urology.2013.12.023

142. Paterson R, Fernandez A, Razvi H, et al. Evaluation and medical management of the kidney stone patient. Can Urol Assoc J 2010;4:375

143. Pearle MS, Goldfarb DS, Assimos DG, et al. Medical management of kidney stones: AUA guideline. J Urol 2014;192:316.

144. Turk C, Knoll T, Petrik A, et al. EAU Guidelines on urolithiasis. http://uroweb.org/wp-content/ uploads/20_Urolithiasis_LR-March-13-2012.pdf. Accessed November 11, 2015.

145. Lojanapiwat $\bar{B}$, Tanthanuch $M$, Pripathanont $C$, et al. Alkaline citrate reduces stone recurrence and regrowth after shockwave lithotripsy and percutaneous nephrolithotomy. Int Braz I Urol 201 1;37:611.

146. El-Gamal 0 , El-Bendary $M$, Ragab $M$, et al. Role of combined use of potassium citrate and tamsulosin in the management of uric acid distal ureteral calculi. Urol Res 2012;40:219.

147. Pearle MS, Pierce HL, Miller GL, et al. Optimal method of urgent decompression of the collecting system for obstruction and infection due to ureteral calculi. J Urol 1998;160:1260.

148. Christoph F, Weikert S, Muller M, et al. How septic is urosepsis? Clinical course of infected hydronephrosis and therapeutic strategies. World J Urol 2005;23:243.

149. Ramsey S, Robertson A, Ablett MJ, et al. Evidence-based drainage of infected hydronephrosis secondary to ureteric calculi. J Endourol 2010;24:185.

150. Yoshimura K, Utsunomiya N, Ichioka K, et al. Emergency drainage for urosepsis associated with upper urinary tract calculi. J Urol 2005; 173:458.

151. Lynch MF, Anson KM, Patel U. Current opinion amongst radiologists and urologists in the UK on percutaneous nephrostomy and ureteric stent insertion for acute renal unobstruction: Results of a postal survey. BJU Int 2006;98:1143.

152. Kumar A, Roberts D, Wood KE, et al. Duration of hypotension before initiation of effective antimicrobial therapy is the critical determinant of survival in human septic shock. Crit Care Med 2006;34:1589.

Correspondence: Dr. Michael Ordon, Division of Urology, Department of Surgery, University of Toronto, Toronto, ON; michael.ordon@utoronto.ca 